\title{
Article
}

\section{Tissue Expansion after Non-Skin-Sparing Mastectomy: A Comparative Study of Expansion Courses of Prepectoral and Subpectoral Tissue Expander Placement with Acellular Dermal Matrix}

\author{
Daiwon Jun $^{1}{ }^{(\mathbb{D}}$, Jin Kwan Kim ${ }^{1}$, Byung Yeun Kwon ${ }^{1}$, Young Jin Kim ${ }^{1}$, Ji Young Rhu ${ }^{2} \mathbb{D}$, Kwan Ho Lee ${ }^{2}$ and Jung \\ Ho Lee ${ }^{1, *(\mathbb{D}}$
}

Citation: Jun, D.; Kim, J.K.; Kwon, B.Y.; Kim, Y.J.; Rhu, J.Y.; Lee, K.H.; Lee, J.H. Tissue Expansion after Non-Skin-Sparing Mastectomy: A Comparative Study of Expansion

Courses of Prepectoral and Subpectoral Tissue Expander Placement with Acellular Dermal Matrix. J. Clin. Med. 2021, 10, 4502. https://doi.org/10.3390/ jcm10194502

Academic Editor: Rossana Berardi

Received: 10 August 2021

Accepted: 28 September 2021

Published: 29 September 2021

Publisher's Note: MDPI stays neutral with regard to jurisdictional claims in published maps and institutional affiliations.

Copyright: (c) 2021 by the authors. Licensee MDPI, Basel, Switzerland. This article is an open access article distributed under the terms and conditions of the Creative Commons Attribution (CC BY) license (https:// creativecommons.org/licenses/by/ $4.0 /)$.
1 Department of Plastic and Reconstructive Surgery, Bucheon St. Mary's Hospital, College of Medicine, The Catholic University of Korea, Seoul 07345, Korea; jundw430@gmail.com (D.J.); jinkwan30@naver.com (J.K.K.); nebyung@naver.com (B.Y.K.); psyjkim@catholic.ac.kr (Y.J.K.)

2 Department of Surgery, Bucheon St. Mary's Hospital, College of Medicine, The Catholic University of Korea, Seoul 07345, Korea; jyses82@naver.com (J.Y.R.); lkhdotcome@naver.com (K.H.L.)

* Correspondence: tfm0822@catholic.ac.kr; Tel.: +82-32-340-7095

Abstract: Although skin- or nipple-sparing mastectomy has been popular in the treatment of breast cancer, the radical excision of breast tissue is unavoidable in certain circumstances. However, the ability of an acellular dermal matrix (ADM) to expand remains questionable, and this situation may further hinder tissue expansion. From October 2017 to January 2020, patients who underwent immediate breast reconstruction with tissue expander placement using ADM whose initial fill volume was less than $50 \mathrm{~mL}$ were retrospectively reviewed. The primary outcomes were the number of visits and number of days required to complete the expansion, and the secondary outcomes were the amount of postoperative expansions, expander fill ratio and expander volume. Between the prepectoral group $(n=26)$ and subpectoral group $(n=39)$, the mean number of days (81.46 days versus 88.64 days, $p=0.365$ ) and mean number of visits (5.08 versus $5.69, p=0.91$ ) required to complete expansion exhibited no significant differences. Additionally, there were no significant differences in the mean amount of postoperative expansion (314.23 mL versus $315.38 \mathrm{~mL}, p=0.950)$, the mean final volume $(353.08 \mathrm{~mL}$ versus $339.62 \mathrm{~mL}, p=0.481)$ or the mean final volume ratio ( 0.89 versus $0.86, p=0.35$ ) between the two groups. Therefore, we suggest that prepectoral tissue expander placement after conventional mastectomy can be a valid option.

Keywords: breast neoplasms; mammaplasty; tissue expansion

\section{Introduction}

The reconstruction of the breast after mastectomy remains one of the major topics in plastic surgery [1]. The tendency to choose prosthetic over autologous breast reconstruction has been gaining momentum because of its simplicity, reliability and rapid recovery after surgery [2]. From a historical perspective, subpectoral placement has been the chosen method for the majority of prosthetic device placements [3]. This procedure involves the devices being placed under the pectoralis major muscle, wherein the lower pole is covered with or without an acellular dermal matrix (ADM). Such a procedure enables the pectoralis major muscle to act as a soft tissue barrier for prosthetic devices, thus decreasing the possibilities of implant extrusion, rippling or capsular contracture. Although successful, problems remain regarding animation deformity and muscle spasms that can occur from the pectoralis major muscle [4]. Furthermore, patients undergoing radiotherapy have been shown to suffer a higher risk of implant displacement due to fibrosis of the pectoralis major muscle $[5,6]$. 
As an alternative, the prepectoral placement of prosthetic devices has been proposed. This method may eliminate the risks of breast deformity and/or implant displacement caused by muscle actions. Additionally, an improvement in postoperative pain caused by submuscular dissection has been reported [7-9]. A recent study also reported that compared to partial subpectoral reconstruction, postoperative complications such as seroma, hematoma and animation deformity were significantly higher in prepectoral reconstruction [10].

Innovations and advancements in breast implants, autologous fat grafting, the use of ADM and the acknowledgment of skin-sparing or nipple-sparing mastectomy have accelerated this trend [11,12]. Based on its advantages, the introduction of ADM has set a monumental landmark in the use of prosthetic breast reconstruction [13], including the reinforcement of soft tissue coverage in skin flaps, the segregation of prosthetic devices, a reduction in the inflammatory response and the minimization of the risk of capsular contracture [14,15].

Although skin-sparing mastectomy has become a standard procedure, the radical excision of breast skin is unavoidable in certain circumstances. In that case, due to the reduction in the skin envelope, the initial fill volume of the tissue expander is greatly reduced. Meanwhile, the ability of ADM to expand remains questionable, and this situation may further hinder tissue expansion [16]. Specifically, it is expected that expanders placed in the prepectoral plane will face greater limitations in expansion compared with those placed in the subpectoral plane, wherein the muscular tissue yields a better capability to stretch.

The aim of this study was to compare expansion courses between the prepectoral group and the subpectoral group after non-skin-sparing mastectomy, wherein the initial fill volume of the expander was limited (less than $50 \mathrm{~mL}$ ). By using the number of visits and number of days required to complete expansion as the primary outcomes, we compared two groups of patients who underwent staged breast reconstruction using ADM. In addition, secondary outcomes were compared, including the mean amount of postoperative expansion (the total amount of infusions performed during the office visits), the expander fill ratio (the cumulative expansion volume divided by the expander volume) and the mean expander volume.

\section{Materials and Methods}

A total of 144 patients who received immediate breast reconstruction with tissue expander placements using ADM from October 2017 to January 2020 were retrospectively reviewed. Among them, a group of 72 patients who had initial fill volumes of less than $50 \mathrm{~mL}$ was recruited for this study. Three patients were lost during the follow-up period, and four patients were excluded due to expander removal. Finally, 65 patients who were able to complete expansion were included in the evaluation. The expansion courses were subsequently compared between the prepectoral group $(n=26)$ and the subpectoral group $(n=39)$ (Figure 1). The type of mastectomy performed was either total mastectomy or modified radical mastectomy. Every patient had unilateral breast reconstruction. The inclusion criteria for prepectoral expander placement were as follows: (1) viable skin flap perfusion on physical examination (color and marginal bleeding) or indocyanine green fluorescence angiography, and (2) a thickness of the skin flap greater than $10 \mathrm{~mm}$. 


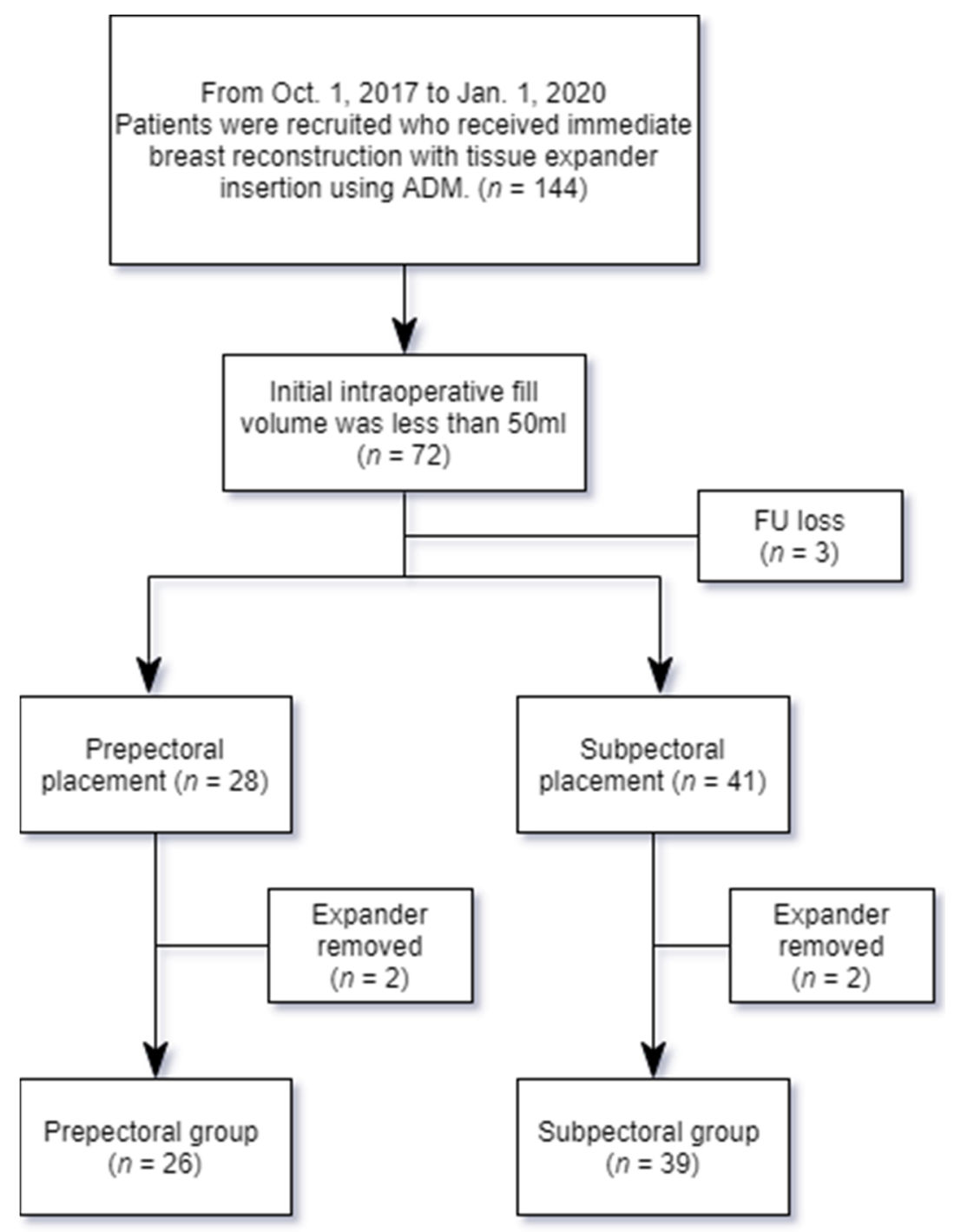

Figure 1. A diagram of the patient recruitment process.

\subsection{Surgical Techniques}

For patients undergoing prepectoral reconstruction, a deflated tissue expander (Mentor Worldwide LLC, Irvine, CA, USA) was placed in the prepectoral space, and suture tabs were fixed to the pectoralis fascia with \#3-0 Vicryl sutures. Inflation of the expander was performed via the maximal infusion of saline until mastectomy wound closure was possible. The volume of expansion in the operating room was defined as the "initial fill volume." ADM (MegaDerm ${ }^{\circledR}$; L\&C Bio Inc, Seoul, Korea), with a thickness of 1 to $2.5 \mathrm{~mm}$, was fenestrated and irrigated prior to insertion. The entire anterior surface of the expander was covered with ADM in vivo, with a basement membrane oriented toward the device. The ADM was sutured to the pectoralis fascia with \#3-0 Vicryl sutures (Figure 2A). One or two drains were inserted around the space between the ADM and the mastectomy skin flap, including the axilla, if necessary.

For patients undergoing subpectoral reconstruction, a subpectoral pocket was created by detaching the inferomedial, inferior and lateral borders of the pectoralis major muscle. After placing the expander under the subpectoral pocket, the suture tabs of the tissue expander were sutured to the periosteum of the ribs with \#3-0 Vicryl sutures. The lower pole of the expander, which was not covered by the pectoralis major muscle, was covered with ADM (Figure 2B). The upper border of the ADM was sutured to the pectoralis muscle with \#3-0 Vicryl sutures, and the lower border of the ADM was sutured to the periosteum of the ribs with \#3-0 Vicryl sutures. The initial expansion was performed in the same 
manner as in the prepectoral reconstruction. One or two drains were inserted around the space between the ADM and the mastectomy skin flap, including the axilla, if necessary.

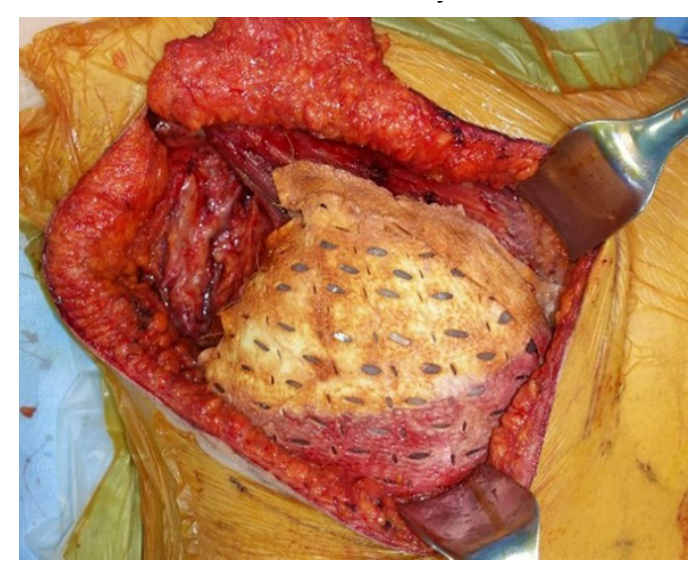

(A)

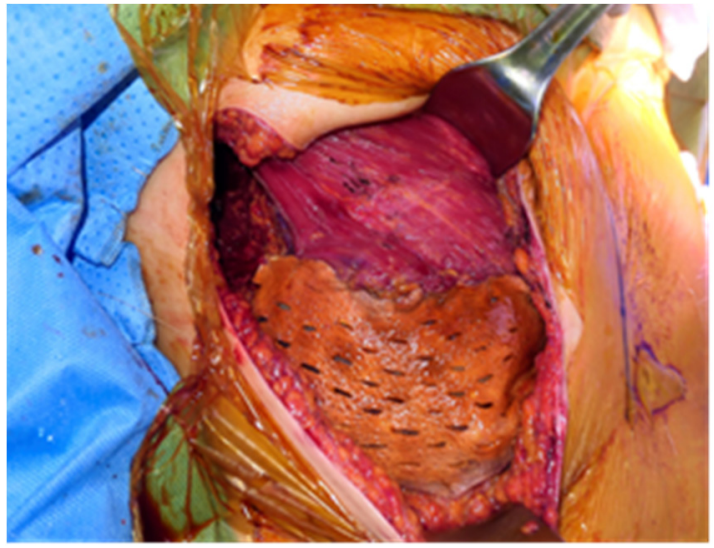

(B)

Figure 2. Intraoperative photographs of prepectoral tissue expander placement (A) and subpectoral tissue expander placement (B).

Expansions were initiated two weeks after surgery in both groups. Each patient visited the office every one or two weeks. At each visit, saline infusion was performed until tightness in the skin flap was observed or if patient discomfort was detected.

\subsection{Postoperative Complications}

Out of the 72 patients who had initial fill volumes of less than $50 \mathrm{~mL}$, three patients were lost during the follow-up period. The complication rate between the prepectoral group $(n=28)$ and the subpectoral group $(n=41)$ was evaluated. Depending on the severity and the required treatment, complications were categorized as either major or minor. Major infection was defined as a culture-proven infection requiring intravenous antibiotic administration or surgical intervention. Major skin necrosis was defined as a full thickness disruption requiring surgical repair. Major seroma was defined as a condition requiring drainage or aspiration. Minor infection was clinically diagnosed and required the administration of oral antibiotics. Minor skin necrosis was defined as superficial wound necrosis that could be managed with the aid of dressings. Minor seroma was defined as a small amount of fluid collection wherein no intervention was required.

\subsection{Statistical Analysis}

All the analyses were performed using IBM SPSS Version 23.0 (IBM Corp., Armonk, NY, USA). Normality was determined by the Shapiro-Wilk test. Normally distributed factors were compared via $t$ tests, and nonnormally distributed variables were evaluated using the Mann-Whitney test. The chi-square test and Fisher's exact test were used to compare categorical variables. A probability of less than $5 \%(p<0.05)$ was used to determine statistical significance.

\section{Results}

\subsection{Patient Characteristics}

Preoperatively, the mean body mass index (BMI) was significantly larger in the prepectoral group. However, a significant difference was not observed in age or history of neoadjuvant chemotherapy, adjuvant chemotherapy or radiotherapy. Patient factors, including diabetes and smoking history, also exhibited no significant differences. Additionally, ductal 
cell carcinoma in situ (DCIS) was the most common tumor stage in the prepectoral group, whereas stage I and stage II tumors were predominant in the subpectoral group (Table 1).

Table 1. Summary of characteristics of patients in the subpectoral and prepectoral groups.

\begin{tabular}{llll}
\hline & Subpectoral & Prepectoral & $p$-Value \\
\hline No. of patients & 39 & 26 & \\
Mean age $\pm \mathrm{SD}$, years & $49.03 \pm 6.88$ & $47.69 \pm 8.31$ & 0.484 \\
Mean BMI $\pm \mathrm{SD}, \mathrm{kg} / \mathrm{m}^{2}$ & $21.71 \pm 2.76$ & $23.60 \pm 2.19$ & 0.005 \\
Neoadjuvant chemotherapy & 4 & 3 & 0.87 \\
Adjuvant chemotherapy & 26 & 17 & 0.916 \\
Adjuvant radiotherapy & 10 & 11 & 0.164 \\
Smoking & 1 & 0 & 1.000 \\
Diabetes & 3 & 5 & 0.250 \\
Tumor stage $(\%)$ & & & \\
$\quad$ DCIS & $11(28 \%)$ & $11(42 \%)$ & \\
Stage I & $12(31 \%)$ & $6(23 \%)$ & \\
Stage II & $12(31 \%)$ & $6(23 \%)$ & \\
Stage III & $3(8 \%)$ & $3(12 \%)$ & \\
Prophylactic & $1(3 \%)$ & $0(0 \%)$ & \\
\hline
\end{tabular}

BMI: body mass index; DCIS: ductal carcinoma in situ; SD: standard deviations.

\subsection{Perioperative Details}

The weight of the excised breast tissue, the area of the excised skin ellipse and the vertical height of the excised skin ellipse demonstrated no statistically significant differences. Total mastectomies were found to be predominant in both groups. The most commonly selected tissue expanders were $350 \mathrm{~mL}$ in both groups. However, the area of ADM coverage was larger in the prepectoral group, and the operation time was significantly longer in the subpectoral group (Table 2).

Table 2. Perioperative details of patients in the subpectoral and prepectoral groups.

\begin{tabular}{|c|c|c|c|}
\hline & Subpectoral & Prepectoral & $p$-Value \\
\hline No. of patients & 39 & 26 & \\
\hline Mastectomy specimen weight (g) & 344.28 & 425.81 & 0.065 \\
\hline Skin ellipse area $\left(\mathrm{cm}^{2}\right)$ & 106.18 & 103.2 & 0.763 \\
\hline Vertical height of skin ellipse $(\mathrm{cm})$ & 7.05 & 6.68 & 0.427 \\
\hline \multicolumn{4}{|l|}{ Mastectomy type $(\%)$} \\
\hline Total mastectomy & $29(74 \%)$ & $17(65 \%)$ & \\
\hline Modified radical mastectomy & $10(26 \%)$ & $9(35 \%)$ & \\
\hline \multicolumn{4}{|l|}{ Expander size $(\%)$} \\
\hline $250 \mathrm{~mL}$ & $0(0 \%)$ & $0(0 \%)$ & \\
\hline $275 \mathrm{~mL}$ & $2(5 \%)$ & $1(4 \%)$ & \\
\hline $350 \mathrm{~mL}$ & $19(49 \%)$ & $14(54 \%)$ & \\
\hline $450 \mathrm{~mL}$ & $16(41 \%)$ & $9(35 \%)$ & \\
\hline $550 \mathrm{~mL}$ & $2(5 \%)$ & $2(8 \%)$ & \\
\hline $\mathrm{ADM} *$ surface area $\left(\mathrm{cm}^{2}\right)$ & 88.69 & 141.53 & $<0.001$ \\
\hline Operation time $(\mathrm{min})$ & 76.56 & 58.46 & $<0.001$ \\
\hline
\end{tabular}

$\mathrm{ADM}^{*}$ : acellular dermal matrix.

\subsection{Expansion Outcomes}

Table 3 demonstrates the primary and secondary outcomes of this study. Primary outcomes, including the number of visits and the total time period required for the completion of the expansion, did not demonstrate significant differences. Secondary outcomes, including the mean amount of postoperative expansion, mean final volume and mean final volume ratio, also did not demonstrate statistically significant differences. 
Table 3. Summary of the primary and secondary outcomes.

\begin{tabular}{llll}
\hline & Subpectoral & Prepectoral & $p$-Value \\
\hline No. of patients & 39 & 26 & \\
Mean time to completion (days) & 88.64 & 81.46 & 0.365 \\
Mean no. of visits for completion & 5.69 & 5.08 & 0.91 \\
Mean amount of postoperative & 315.38 & 314.23 & 0.950 \\
expansion (mL) & 339.62 & 353.08 & 0.481 \\
Mean final volume (mL) & 0.86 & 0.89 & 0.35 \\
Mean final volume ratio & & & \\
\hline
\end{tabular}

Tables 4-6 demonstrate the expansion courses in detail. Only the intraoperative infusions and the first infusions performed during the office visits were significantly greater in the prepectoral group; no differences were found in the following expansions (Table 4). The prepectoral group had a significantly greater mean expander volume intraoperatively and with the 1st, 2nd and 3rd expansions; however, no differences were found in the following expansions (Table 5). The prepectoral group also had a significantly greater intraoperative expander fill ratio, as well as with the 1st, 2nd and 3rd expansions. No differences were found in the following expansions (Table 6).

Table 4. Comparison of the expansion process between the subpectoral and prepectoral groups according to the mean amount of expansion per visit.

\begin{tabular}{llll}
\hline $\begin{array}{c}\text { Mean Amount of } \\
\text { Expansion Per Visit (mL) }\end{array}$ & Subpectoral $(\boldsymbol{n = 3 9 ,} \mathbf{0})$ & Prepectoral $(\boldsymbol{n = 2 6 , \mathbf { o } )}$ & $\boldsymbol{p}$-Value \\
\hline Intraoperative & $27.9(100 \%)$ & $41.5(100 \%)$ & 0.011 \\
1st postoperative & $57.1(100 \%)$ & $68.8(100 \%)$ & 0.014 \\
2nd postoperative & $65.5(100 \%)$ & $71.7(100 \%)$ & 0.236 \\
3rd postoperative & $63.1(100 \%)$ & $63.6(96 \%)$ & 0.955 \\
4th postoperative & $60.3(100 \%)$ & $55.6(96 \%)$ & 0.337 \\
5th postoperative & $49.2(82 \%)$ & $55(73 \%)$ & 0.582 \\
6th postoperative & $41.2(43 \%)$ & $38.2(42 \%)$ & 0.675 \\
7th postoperative & $32.5(15 \%)$ & $35(7 \%)$ & 1.00 \\
\hline
\end{tabular}

Table 5. Comparison of the expansion process between the subpectoral and prepectoral groups according to the mean expander volume.

\begin{tabular}{llll}
\hline $\begin{array}{c}\text { Mean Expander } \\
\text { Volume }(\mathbf{m L})\end{array}$ & Subpectoral $(\boldsymbol{n = 3 9 )}$ & Prepectoral $(\boldsymbol{n = 2 6 )}$ & $\boldsymbol{p}$-Value \\
\hline Intraoperative & 27.9 & 41.5 & 0.011 \\
1st postoperative & 85 & 111.1 & 0.014 \\
2nd postoperative & 150.5 & 183.8 & 0.030 \\
3rd postoperative & 213.5 & 246.9 & 0.037 \\
4th postoperative & 275.4 & 300.6 & 0.106 \\
5th postoperative & 319.5 & 350.8 & 0.208 \\
6th postoperative & 345.3 & 386.3 & 0.378 \\
7th postoperative & 366.6 & 385 & 0.429 \\
\hline
\end{tabular}

Table 6. Comparison of the expansion process between the subpectoral and prepectoral groups according to the expander fill ratio.

\begin{tabular}{llll}
\hline Expander Fill Ratio & Subpectoral $(\boldsymbol{n}=\mathbf{3 9 )}$ & Prepectoral $(\boldsymbol{n}=\mathbf{2 6})$ & $\boldsymbol{p}$-Value \\
\hline Intraoperative & 0.07 & 0.11 & 0.013 \\
1st postoperative & 0.21 & 0.28 & 0.022 \\
2nd postoperative & 0.38 & 0.46 & 0.026 \\
3rd postoperative & 0.54 & 0.63 & 0.036 \\
4th postoperative & 0.69 & 0.76 & 0.122 \\
5th postoperative & 0.85 & 0.85 & 0.178 \\
6th postoperative & 0.87 & 0.96 & 0.111 \\
7th postoperative & 0.85 & 0.96 & 0.071 \\
\hline
\end{tabular}




\subsection{Postoperative Complications}

No significant difference was found in the overall complication rate between the two groups (Table 7). In each group, two patients received expander removal due to infection.

Table 7. Comparison of postoperative complications between the subpectoral and prepectoral groups.

\begin{tabular}{llll}
\hline Complication & Subpectoral & Prepectoral & $p$-Value \\
\hline No. of expanders & 41 & 28 & 0.799 \\
Any complication & 12 & 9 & \\
Major complications & 9 & 8 & \\
Infection & 5 & 5 & \\
Skin necrosis & 3 & 2 & \\
Seroma & 1 & 1 & \\
Minor complications & 3 & 1 & \\
Infection & 2 & 1 & \\
Skin necrosis & 1 & 0 & \\
Seroma & 0 & 0 & \\
\hline
\end{tabular}

\section{Discussion}

Breast reconstruction using prosthetic devices has been a primary reconstruction option for decades due to its relative simplicity and rapid recovery compared to autologous reconstruction [17]. Prosthetic breast reconstruction can be performed in one- or two-stage operations. The one-stage (direct-to-implant) approach can only be performed in carefully selected patients who have adequate soft tissue coverage. More than $80 \%$ of prosthetic breast reconstructions are performed in two-stage operations due to predictable outcomes and a required time period for pathological confirmation [18].

The revolution in prosthetic devices and the introduction of ADM have popularized the use of prepectoral breast reconstruction. As an alternative to subpectoral placement, prepectoral placement can provide ideal device positioning and eliminate pectoralis major muscle spasms and animation deformities [19]. The use of ADM facilitates the control of the mastectomy space and prosthetic devices; thus, improved aesthetic outcomes can be achieved [13]. ADM is known to minimize fibrosis and promote vascularization in the periprosthetic environment [20], and it also has protective effects regarding both capsular contracture and post-radiotherapy complications [21].

Approaches to mastectomy have evolved in parallel with advancements in prosthetic devices. To preserve the breast skin envelope and facilitate breast reconstruction, modifications in the mastectomy technique have been vigorously sought. Such efforts have proven to provide greater patient satisfaction and equivalent overall survival [22,23]. Therefore, modern mastectomy techniques, i.e., skin-sparing mastectomy (SSM) and nipple-sparing mastectomy (NSM), have become widely accepted [24-26]. However, skin preservation is not always possible. In certain situations, such as the proximity of tumors to the skin or skin involvement with the tumor, the radical excision of breast skin is inevitable.

In breast reconstruction after non-skin-sparing mastectomy, the initial fill volume of the expander can be limited due to skin shortages. In this situation, the size of the ADM overlying the deflated expander will be smaller, and the prepectoral pocket created by the $\mathrm{ADM}$ will also be finite. For instance, the mean initial fill volume of the prepectoral group in our study was significantly less than that in other studies of prepectoral expansion ( $41.5 \mathrm{~mL}$ versus $223.4 \mathrm{~mL}$ by Zhu et al.; $41.5 \mathrm{~mL}$ versus $372 \mathrm{~mL}$ by Wormer et al.) [27,28]. In addition, the amount of ADM required to create a prepectoral pocket was significantly less in our study than in other studies ( $141.53 \mathrm{~cm} 2$ versus $320 \mathrm{~cm} 2$ by Wormer et al.) [27]. For that reason, the ability of ADM to expand is of importance in prepectoral breast reconstruction after non-skin-sparing mastectomy.

The elastic potential of ADM has been demonstrated in various fields of medicine. In the repair of abdominal hernias, ADM has maintained its integrity in more than $95 \%$ of cases [29]. However, in the repair of bladder and vaginal suspensions, only $50 \%$ were able 
to achieve the desired result [30]. The ability of ADM to stretch is dependent on various factors, such as the recipient environment and the manner of application (i.e., inlay versus onlay or dermal side up versus dermal side down) [31]. When assuming the environment of the recipient site and the manner of application, the properties of ADM used in abdominal hernias are comparable to those of ADM used in breast reconstruction. Only one study has been conducted to evaluate the elastic properties of ADM used in breast reconstruction. Yang et al. reported that although inserted ADM is resistant to expansion, the pectoralis major muscle and surrounding tissues compensate for the amount of expansion [16]. The above findings suggest that the expansion capability of prepectoral tissue expanders is expected to encounter greater limitations compared to subpectoral tissue expanders. However, our findings suggest that the number of visits and the number of days required to complete expansion did not significantly differ between the two groups. There were significant differences in expander volume and expander fill ratio during the early phase of expansion (i.e., intraoperative to the 3 rd postoperative visit) between the groups. However, this can be interpreted by the fact that the differences in the initial fillings were based on higher BMI values in the prepectoral group at baseline. Due to the inclusion criteria, patients with abundant soft tissue were recruited for prepectoral expander placement. Regarding the amount of expansion performed during office visits, only the first infusion was significantly greater in the prepectoral group.

After interpreting the expansion courses, we postulated two possible explanations. First, although questionable, the lack of ability of ADM to stretch is not significant enough to limit expansion. Second, elongation of the scar tissue that formed between the ADM and native tissue (pectoralis fascia) may have compensated for the limitation of ADM stretching. The authors were able to observe a number of elongated capsules between the $\mathrm{ADM}$ and the pectoralis muscle fascia during the 2nd stage of the operation in prepectoral tissue expansion cases (Figure 3).

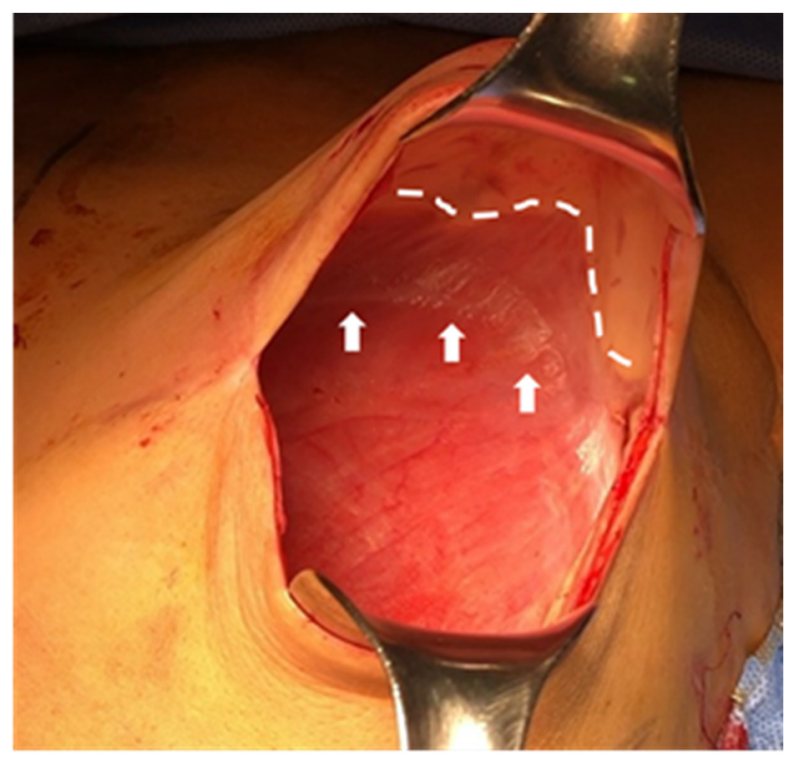

Figure 3. Intraoperative photograph of elongated capsule formation between the acellular dermal matrix (ADM) and the pectoralis muscle fascia. The margin of the pectoralis muscle fascia is indicated with arrows $(\uparrow)$, and the margin of the ADM is indicated by the dashed line.

Our study was confined to the use of thick ADM. Thus, the impact of the thickness of the ADM on expansion was not considered. In addition, future research regarding synthetic mesh-assisted breast reconstruction is warranted. A recent study has demonstrated that in partial subpectoral implant placement, polypropylene mesh-assisted reconstruction showed a significantly lower complication rate compared to ADM-assisted reconstruction [32]. Furthermore, the study design was retrospective in nature. Therefore, it is not free 
from selection bias, wherein patients with relatively healthy skin flaps were included in the prepectoral group. Finally, due to the relatively short period of the follow-up, long-term postoperative complications, such as animation deformities and capsular contracture, were not considered.

\section{Conclusions}

ADM has become an essential component in breast reconstruction. However, the ability of ADM to stretch is relatively inferior to that of native tissue. In this study, we compared the expansion courses of prepectoral and subpectoral groups with initial fill volumes less than $50 \mathrm{~mL}$. The prepectoral group had a greater mean expander volume and expander fill ratio in the early period of expansion. However, no differences were found in the number of visits or days required for the completion of the expansion. These findings indicate that ADM does not hinder breast tissue expansion. Accounting for the multiple advantages of prepectoral expander placement, i.e., the ease of operation, decreased animation deformity, less pain and improved aesthetic outcomes, prepectoral tissue expander placement can be performed in conventional mastectomy patients even when only a limited space is allowed for expansion.

Author Contributions: Conceptualization, J.H.L.; methodology, J.Y.R. and K.H.L.; analysis and validation, B.Y.K. and Y.J.K.; formal analysis, J.K.K.; data curation, D.J.; writing-original draft preparation, D.J.; writing-review and editing, J.H.L.; visualization, J.K.K.; supervision and project administration, J.H.L. All authors have read and agreed to the published version of the manuscript.

Funding: The authors have no financial interests to declare in relation to the contents of this article and have received no financial support in the preparation of this article.

Institutional Review Board Statement: This study was conducted according to the guidelines of the Declaration of Helsinki and approved by the Institutional Review Board of Bucheon St. Mary's Hospital (protocol code HC21RISI0087; date: 17 August 2021).

Informed Consent Statement: Written informed consent was obtained from the patients to publish this paper.

Data Availability Statement: The data presented in this study are available on request from the corresponding author. The data are not publicly available due to privacy or ethical issues.

Conflicts of Interest: The authors declare no conflict of interest.

\section{References}

1. American Society of Plastic Surgeons. Plastic Surgery Statistics Report. Available online: https://www.plasticsurgery.org/ documents/News/Statistics/2020/plastic-surgery-statistics-full-report-2020.pdf?_gl=1*1072zc2*_ga*MTE5NTM5MDI0OC4 xNjI2OTIwNDQx*_ga_2N9PTXXTDN*MTYyNjkyMDQ0MC4xLjEuMTYyNjkyMDUxMS41OQ (accessed on 22 July 2021).

2. Gurunluoglu, R.; Gurunluoglu, A.; Williams, S.A.; Tebockhorst, S. Current trends in breast reconstruction: Survey of American Society of Plastic Surgeons 2010. Ann. Plast. Surg. 2013, 70, 103-110. [CrossRef]

3. Nahabedian, M.Y.; Jacobson, S.R. Two-stage prepectoral breast reconstruction. Gland. Surg. 2019, 8, 43-52. [CrossRef]

4. Becker, H.; Fregosi, N. The Impact of Animation Deformity on Quality of Life in Post-Mastectomy Reconstruction Patients. Aesthet. Surg. J. 2017, 37, 531-536. [CrossRef]

5. Nguyen, J.T.; Buchanan, I.A.; Patel, P.P.; Aljinovic, N.; Lee, B.T. Intercostal neuroma as a source of pain after aesthetic and reconstructive breast implant surgery. J. Plast. Reconstr. Aesthetic Surg. 2012, 65, 1199-1203. [CrossRef] [PubMed]

6. Ducic, I.; Seiboth, L.A.; Iorio, M.L. Chronic postoperative breast pain: Danger zones for nerve injuries. Plast. Reconstr. Surg. 2011, 127, 41-46. [CrossRef] [PubMed]

7. Gabriel, A.; Sigalove, S.; Sigalove, N.M.; Storm-Dickerson, T.L.; Rice, J.; Pope, N.; Maxwell, G.P. Prepectoral Revision Breast Reconstruction for Treatment of Implant-Associated Animation Deformity: A Review of 102 Reconstructions. Aesthet. Surg. J. 2018, 38, 519-526. [CrossRef] [PubMed]

8. Sigalove, S.; Maxwell, G.P.; Sigalove, N.M.; Storm-Dickerson, T.L.; Pope, N.; Rice, J.; Gabriel, A. Prepectoral Implant-Based Breast Reconstruction: Rationale, Indications, and Preliminary Results. Plast. Reconstr. Surg. 2017, 139, 287-294. [CrossRef]

9. Cattelani, L.; Polotto, S.; Arcuri, M.F.; Pedrazzi, G.; Linguadoca, C.; Bonati, E. One-Step Prepectoral Breast Reconstruction with Dermal Matrix-Covered Implant Compared to Submuscular Implantation: Functional and Cost Evaluation. Clin. Breast Cancer 2018, 18, e703-e711. [CrossRef] 
10. Ribuffo, D.; Berna, G.; De Vita, R.; Di Benedetto, G.; Cigna, E.; Greco, M.; Valdatta, L.; Onesti, M.G.; Torto, F.L.; Marcasciano, M. Dual-plane retro-pectoral versus pre-pectoral DTI breast reconstruction: An italian multicenter experience. Aesthetic Plast. Surg. 2021, 45, 51-60. [CrossRef]

11. Maxwell, G.P.; Gabriel, A. Bioengineered Breast: Concept, Technique, and Preliminary Results. Plast. Reconstr. Surg. 2016, 137, 415-421. [CrossRef]

12. Maxwell, G.P.; Gabriel, A. The evolution of breast implants. Plast. Reconstr. Surg. 2014, 134, 12S-17S. [CrossRef]

13. Nahabedian, M.Y. Acellular dermal matrices in primary breast reconstruction: Principles, concepts, and indications. Plast. Reconstr. Surg. 2012, 130, 44S-53S. [CrossRef] [PubMed]

14. Macadam, S.A.; Lennox, P.A. Acellular dermal matrices: Use in reconstructive and aesthetic breast surgery. Can. J. Plast. Surg. 2012, 20, 75-89. [CrossRef] [PubMed]

15. Phillips, B.T.; Bishawi, M.; Dagum, A.B.; Bui, D.T.; Khan, S.U. A systematic review of infection rates and associated antibiotic duration in acellular dermal matrix breast reconstruction. Eplasty 2014, 14, e42. [PubMed]

16. Yang, C.E.; Park, K.H.; Lee, D.W.; Lew, D.H.; Song, S.Y. Does acellular dermal matrix expand in response to tissue expander inflation? Arch. Plast. Surg. 2019, 46, 34. [CrossRef] [PubMed]

17. Albornoz, C.R.; Bach, P.B.; Mehrara, B.J.; Disa, J.J.; Pusic, A.L.; McCarthy, C.M.; Cordeiro, P.G.; Matros, E. A paradigm shift in US breast reconstruction: Increasing implant rates. Plast. Reconstr. Surg. 2013, 131, 15-23. [CrossRef] [PubMed]

18. Davila, A.A.; Mioton, L.M.; Chow, G.; Wang, E.; Merkow, R.P.; Bilimoria, K.Y.; Fine, N.; Kim, J.Y. Immediate two-stage tissue expander breast reconstruction compared with one-stage permanent implant breast reconstruction: A multi-institutional comparison of short-term complications. J. Plast. Surg. Hand Surg. 2013, 47, 344-349. [CrossRef]

19. Sbitany, H.; Piper, M.; Lentz, R. Prepectoral Breast Reconstruction: A Safe Alternative to Submuscular Prosthetic Reconstruction following Nipple-Sparing Mastectomy. Plast. Reconstr. Surg. 2017, 140, 432-443. [CrossRef]

20. Basu, C.B.; Leong, M.; Hicks, M.J. Acellular cadaveric dermis decreases the inflammatory response in capsule formation in reconstructive breast surgery. Plast. Reconstr. Surg. 2010, 126, 1842-1847. [CrossRef]

21. Nahabedian, M.Y. AlloDerm performance in the setting of prosthetic breast surgery, infection, and irradiation. Plast. Reconstr. Surg. 2009, 124, 1743-1753. [CrossRef]

22. Galimberti, V.; Vicini, E.; Corso, G.; Morigi, C.; Fontana, S.; Sacchini, V.; Veronesi, P. Nipple-sparing and skin-sparing mastectomy: Review of aims, oncological safety and contraindications. Breast 2017, 34 (Suppl. 1), S82-S84. [CrossRef]

23. Lanitis, S.; Tekkis, P.P.; Sgourakis, G.; Dimopoulos, N.; Al Mufti, R.; Hadjiminas, D.J. Comparison of skin-sparing mastectomy versus non-skin-sparing mastectomy for breast cancer: A meta-analysis of observational studies. Ann. Surg. 2010, 251, 632-639. [CrossRef]

24. Mallon, P.; Feron, J.G.; Couturaud, B.; Fitoussi, A.; Lemasurier, P.; Guihard, T.; Cothier-Savay, I.; Reyal, F. The role of nipple-sparing mastectomy in breast cancer: A comprehensive review of the literature. Plast. Reconstr. Surg. 2013, 131, 969-984. [CrossRef]

25. Spear, S.L.; Willey, S.C.; Feldman, E.D.; Cocilovo, C.; Sidawy, M.; Al-Attar, A.; Hannan, C.; Seiboth, L.; Nahabedian, M.Y. Nipple-sparing mastectomy for prophylactic and therapeutic indications. Plast. Reconstr. Surg. 2011, 128, 1005-1014. [CrossRef]

26. Murthy, V.; Chamberlain, R.S. Defining a place for nipple sparing mastectomy in modern breast care: An evidence based review. Breast J. 2013, 19, 571-581. [CrossRef] [PubMed]

27. Wormer, B.A.; Valmadrid, A.C.; Ganesh Kumar, N.; Al Kassis, S.; Rankin, T.M.; Kaoutzanis, C.; Higdon, K.K. Reducing Expansion Visits in Immediate Implant-Based Breast Reconstruction: A Comparative Study of Prepectoral and Subpectoral Expander Placement. Plast. Reconstr. Surg. 2019, 144, 276-286. [CrossRef]

28. Zhu, L.; Mohan, A.T.; Abdelsattar, J.M.; Wang, Z.; Vijayasekaran, A.; Hwang, S.M.; Tran, N.V.; Saint-Cyr, M. Comparison of subcutaneous versus submuscular expander placement in the first stage of immediate breast reconstruction. J. Plast. Reconstr. Aesthet. Surg. 2016, 69, e77-e86. [CrossRef] [PubMed]

29. Buinewicz, B.; Rosen, B. Acellular cadaveric dermis (AlloDerm): A new alternative for abdominal hernia repair. Ann. Plast. Surg. 2004, 52, 188-194. [CrossRef] [PubMed]

30. Clemons, J.L.; Myers, D.L.; Aguilar, V.C.; Arya, L.A. Vaginal paravaginal repair with an AlloDerm graft. Am. J. Obstet. Gynecol. 2003, 189, 1612-1618, discussion 1618-1619. [CrossRef]

31. Nahabedian, M.Y. Does alloderm stretch? Plast. Reconstr. Surg. 2007, 120, 1276-1280. [CrossRef]

32. Schüler, K.; Paepke, S.; Kohlmann, T.; Alwafai, Z.; Nawroth, F.; Zygmunt, M.; Ohlinger, R. Postoperative Complications in Breast Reconstruction with Porcine Acellular Dermis and Polypropylene Meshes in Subpectoral Implant Placement. In Vivo 2021, 35 , 2739-2746. [CrossRef] [PubMed] 